This item was submitted to Loughborough's Research Repository by the author.

Items in Figshare are protected by copyright, with all rights reserved, unless otherwise indicated.

\title{
Reset to zero and specify active safety systems according to real world needs
}

PLEASE CITE THE PUBLISHED VERSION

PUBLISHER

(C) ASCE

VERSION

AM (Accepted Manuscript)

LICENCE

CC BY-NC-ND 4.0

\section{REPOSITORY RECORD}

Gkikas, Nikolaos, John H. Richardson, and Julian Hill. 2019. "Reset to Zero and Specify Active Safety Systems According to Real World Needs”. figshare. https://hdl.handle.net/2134/5013. 
This item was submitted to Loughborough's Institutional Repository (https://dspace.lboro.ac.uk/) by the author and is made available under the following Creative Commons Licence conditions.

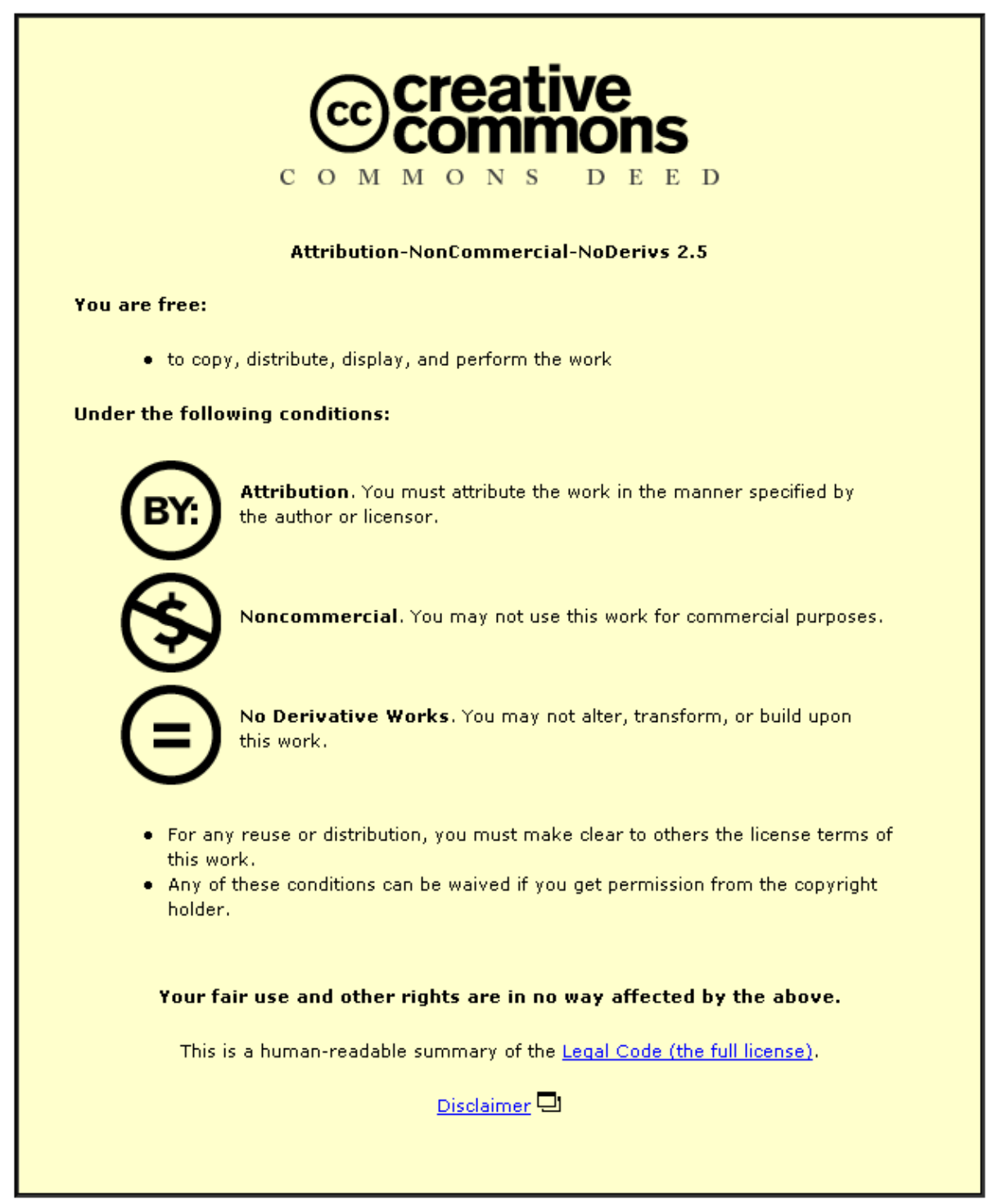

For the full text of this licence, please go to: http://creativecommons.org/licenses/by-nc-nd/2.5/ 


\title{
RESET TO ZERO AND SPECIFY ACTIVE SAFETY SYSTEMS
}

\section{ACCORDING TO REAL-WORLD NEEDS}

\author{
Nikolaos Gkikas ${ }^{1}$, Julian R. Hill ${ }^{2}$, John H. Richardson ${ }^{3}$
}

\begin{abstract}
Emergency Brake Assist (EBA), Adaptive Cruise Control (ACC) and alternative instantiations of intelligent vehicle control systems aspire to support the driver in controlling the vehicle and alleviate the incidents that would lead to collisions and injury. This paper resets to zero and based on data from the On-The-Spot (OTS) accident study challenges the capability of active safety systems to aim at the sources of longitudinal control failures. The road user interactions file from 3024 road accidents in Thames Valley and Nottinghamshire in UK was analysed. Interactions where "failure to stop" or "sudden braking” is the precipitating factor are analysed and the main contributory factors are identified. Some of those factors are addressed by current and coming technologies - like low road friction, excessive speed and close following, but other common ones are significantly neglected - like distraction, failure to judge other person’s path, failure to look, and “look but did not see” instances.
\end{abstract}

\footnotetext{
${ }^{1} \mathrm{PhD}$ Candidate, Ergonomics \& Safety Research Institute, Loughborough University, Loughborough, UK, email: N.Gkikas@lboro.ac.uk

${ }^{2}$ Research Fellow, Vehicle Safety Research Centre, Loughborough University, Loughborough, UK, e-mail: J.R.Hill@lboro.ac.uk

${ }^{3}$ Director, Ergonomics \& Safety Research Institute, Loughborough University, Loughborough, UK, e-mail:

J.H.Richardson@lboro.ac.uk
} 


\section{INTRODUCTION}

Rear end collisions and are the most common type of road accidents and fortunately the ones with fewer fatalities (Fatality analysis reporting system (FARS) web-based encyclopedia. data files and procedures to analyse them.2005; Evans, 2004; Lee, 2006). However because of its prevalence, the cost of property damage (Blincoe et al., 2002) and the long term cost of injury (Barnes \& Thomas, 2006; Barnes, 2006), the impact on society is comparable, if not greater, than loss of control/single car accidents - which are associated with more fatalities. The latter type of collision is associated with failure in lateral controllability while rear shunts relate with longitudinal control failures at the basic level of the driving task.

There are many different descriptions and models about the driving task depending on the context in which the author develops it. From the early 40s till today driving has been described as a safe field of travel in which drivers adjust their speed and direction avoiding hazards and moving towards their destination (Gibson \& Crooks, 1938), as an intermittent monitoring task (Senders, Kristofferson, Levison, Dietrich, \& Ward, 1967) and other timebased descriptions (Godthelp, Milgram, \& Blaauw, 1984; Van Winsum \& Godthelp, 1996; Van Winsum \& Heino, 1996; Van Winsum \& Brouwer, 1997; van Winsum, Brookhuis, \& de Waard, 2000/1), as a threat avoidance (Fuller, 1984), and finally as control actions used to adjust the state of the vehicle in response to sic perturbations (D. H. Weir \& McRuer, 1970; D. H. Weir \& Mcruer, 1973). All the above descriptions, no matter the differences among them, suggest a basic level of the driving task consisting of the longitudinal and the lateral control of the vehicle. This is instantiated through manipulation of brake/throttle pedals and steering wheel inputs respectively. 
Bearing in mind the notion above, manufacturers and system developers suggest a series of vehicle systems supposed to help the driver in their task. Generally, there are four main types of systems already in production. These are the Adaptive Cruise Control (ACC) and the likes, Electronic Stability Program (ESP) and the likes, Lane Change Support (LCS) and the likes, and Emergency Brake Assist (EBA). Details about the functionality and the notion of the above is widely available (BOSCH, 2000; Society for Automotive Engineers, 1999; Delphi active safety products for automotive manufacturers.; Honda safety - active safety.). As active safety systems, their effect in accident mitigation has recently been supported by some statistical evidence (Breuer, Faulhaber, Frank, \& Gleissner, 2007; Lie, Tingvall, Krafft, \& Kullgren, 2006; Page, Foret-Bruno, \& Cuny ; Thomas, 2006). However, those macroscopic studies feature all the limitations of field correlation based analyses - loads of possible confounding variables and methodological inability to infer causation (Breakwell, Hammond, \& Fife-Schaw, 2000). Furthermore, auto-brake systems like the City Safe ${ }^{\circledR}$ by Volvo have recently entered the mass market promising to mitigate rear-end collisions in urban environments. However, an issue that has not been satisfactorily addressed is how much these systems aim at the cause of the accidents they are supposed to resolve.

Considering the above, an examination of the characteristics of "failure to stop" and "sudden braking” accidents from the On-the-Spot Accident (OTS) Investigation study (Hill, Thomas, Smith, \& Byard, 2006) was carried out. OTS, as its name implies in a project run in cooperation with the police authorities in two main areas of UK; namely Thames Valley and Nottinghamshire. Accident investigators are able to arrive on the spot within minutes after an accident has happened and collect volatile data that would otherwise be lost.

\section{The history behind OTS}


Although a comparatively new microscopic accident investigation study, OTS comes out of the long tradition of accident investigation in the UK. A more detailed description of this tradition is provided in another publication (Gkikas, Hill, \& Richardson, 2008). The necessary milestones are:

1. The beginning of road accident data in 1909 (Hillard, Logan, \& Fildes, 2005).

2. The introduction of a nationwide system for accident data collection in 1949, namely STATS19. The original system collected both objective factors (speed limit, time, weather etc.) as well as contributory factors, i.e. the factors which the reporting officer on the accident scene believed that had contributed to accident occurrence.

3. In the ' 90 s, the development of the "new system for recording contributory factors in road accidents” (Broughton, 1997). The suggested system was an amalgam of the theoretical model suggested by Leeds University during the late 80’s (Carsten, Tight, Southwell, \& Plows, 1989), plus the aggregated experience and practical needs indicated by the police forces. Therefore, a two-level hierarchy with the following terminology was developed:

- Precipitating factors are the failures and manoeuvres that immediately led to the accident.

- Contributory factors are the causes for these failures and manoeuvres. A recorded contributory factor always relates to a precipitating factor that has already been recorded.

4. The consecutive reviews in the year 2000 (Neilson \& Condon, 2000) and 2002 (Wilding, 2002) that suggested itemised amendments and especially the latter acknowledged the internal "blame machine" of the system, as it tended to lay blame 
on an individual and was totally inappropriate for accidents were there was contribution from multiple road users.

5. The report by Hickford \& Hall (2004) and its outcome, the STATS19 (2005) contributory factors form now in use, including seventy-six contributory factors and also an option to report “other factor” by text description.

Since the year 2000, in parallel and based on the experience of accident data coding from STATS19 and microscopic on-the-spot studies in Germany (Otte, 1999) and France (Girard, 1993), OTS project commenced in the UK (Hill et al., 2006). Against the traditional retrospective studies, where accident data is collected long after an accident occurred the OTS offers the ability to collect invaluable data which would otherwise be lost such as vehicle rest position, debris locations, weather conditions, road surface conditions, tyre pressures, temporary changes in the road environment at the time of impact, immediate driver and witness descriptions. In addition to this, it includes data which is collected retrospectively in days or months after the accident (road signs, impact damage on vehicles, road dimensions etc.).

The procedure on the scene starts with the arrival of the investigation team at the scene of an accident. The serving police officer on the OTS team makes contact with the police officer in charge of the accident scene and briefs him about the intended activities of the investigators. After fulfilment of protocols and safety issues, the team makes contact with the people and the various elements involved in the crash. Data is coded in a database of 200 forms with over 3000 variables. Within those, as with any accident in the UK, a contributory factors form similar to the STATS19 one described earlier is included. Thus accident causation is coded in two levels: a precipitating factor and up to six contributory ones. 
OTS cases are further analysed to determine more complex descriptions of accident causation in terms of possible interactions between the active road users. A system called "interactions" has been developed to allow analysis and recording of one or more interactions between each road user and his environment to provide description of events leading to impact at any degree of necessary complexity. This allows acquisition of information at a microscopic level, where each person can be involved, affect and be affected by multiple agents of the road traffic environment. All information is completely anonymous and does not include personal details or other documents. The project has been operational since the year 2000 and is now in its third phase.

\section{ANALYSIS OF CASES WHERE “FAILURE TO STOP” OR “SUDDEN BRAKING” INITIATED THE ACCIDENT}

With regard to vehicle control, there are two types of failures coded as precipitating factors in the database directly pertinent to longitudinal controllability. The first is a basic failure to stop the vehicle when necessary, and the second is stopping the vehicle at an inappropriate time or stopping in an abrupt manner. Therefore, the current study examined as a first step only the accident cases where "failure to stop" or "sudden braking” were the identified precipitating factor of the accident. However the data presented below takes advantage of the microscopic detail the multiple interactions/road user/case analysis has to offer. Thus, the following analysis is based on 1099 interactions in "failure to stop" accidents and 152 interactions in "sudden braking" accidents. The database has been compared against STATS19 data and validated as representative of accidents in the UK (Hill et al., 2006). All 
results presented hereafter have been tested for asymptotic significance (chi-square test) and found below the criterion $\mathrm{a}=0.01$.

\section{"Failure to stop"}

Failure of a driver/vehicle to stop in time to avoid collision with another road user or object is identified as the precipitating factor in 301 cases investigated by the OTS team. "Failure to stop" therefore defines a unique set of accidents where that is the single, precipitating factor causing the accident. Clearly all accidents are in some way the result of a failure to stop before the collision occurs, but the sub-set under study here represent drivers who were considered to be the predominate, precipitating cause of their accident by failing to stop their vehicle in time. Each "failure to stop" will have been assigned as the precipitating factor following an accident investigation to eliminate other possible precipitating factors, such as for example, the driver travelling too fast, or a pedestrian stepping into the road. This is therefore a set of drivers who were not able to stop for a variety of personal psychological or other reasons. There will of course be other drivers who did not stop before collision (all the other drivers in the database). This study focuses, however, on the unique group for which "failure to stop" was the precipitating factor, together with an additional "sudden braking” group, as explained below. This study does not therefore attempt to consider all possible reasons for drivers failing to stop in time to avoid their accident.

Experience of accident investigation in high-hazard industry, aerospace, space and road traffic applications (Kirwan, 1994; Reason, 1990; Columbia Accident Investigation Board, 2003; Whittingham, 2004) indicates that we must first define a precipitating factor, but that it is equally important to then understand the additional contributory factors. 
Therefore it is necessary not only to focus on the predominant factor that triggered the accident, but also to look further into the factors that contributed to the occurrence of an accident. Table 1 presents the predominant contributory factors in cases where "failure to stop” is acknowledged as the single precipitating factor. In a previous study based on the (coded by the police officer) Contributory Factors 2005 data (Gkikas, Hill, \& Richardson, 2008), driver's "too close" car following strategy is identified as the most common contributory factor in accidents followed by failures to obey traffic signals and overspeeding for the conditions present. Cognitive failures - to look and to judge other paths - and inappropriate reactions - sudden braking - are also commonly found in such accidents.

Further examination of the data coded by OTS investigators in the accident causation files reveals a more detailed picture. Additional contribution is founded in psychological factors such as distraction, panic behaviour, nervousness and inattention (tables 2, 3). Inattention was found causative in between 19.5\%-73.3\% of interactions, while another four (failure to judge other's path or speed, failure to look, lack of judgement of own path, and "look but did not see") cognitive failures have at list "possible" involvement in $24 \%-32 \%$ of interactions. Carelessness/recklessness/thoughtlessness is the predominant emotional factor with estimated involvement between $18.6 \%$ and $50.4 \%$ of all interactions. "In a hurry" and aggressive driving are involved to an aggregate up to $27.7 \%$ of interactions as well. In terms of who is involved in such accidents, most are male drivers - 52\% against $36.6 \%$ female and $11 \%$ unspecified - and most are car occupants.

One of the common misconceptions is that accidents triggered by a failure to stop a vehicle in time are only rear end collisions happening during car - following settings. Common 
collision types associated with such accidents also include crossing, merging, right turns, pedestrian crossings and more (Gkikas et al., 2008).

\section{Sudden braking}

Starting from where we left with the previous type of accidents, a similar variety of collisions applies here as well (Gkikas et al., 2008). Rear end collisions are the most common case, but not the only. Loss off control in cornering (left), missing intersections, loss of control on curves and going off road are common collisions initiated by the sudden braking of a leading vehicle. In total $18 \%$ of the cases initiated by sudden brake application lead to collisions of these types. Another $7.9 \%$ of those cases involved side- and head-on collisions during overtaking, while an interesting $5.3 \%$ includes collision with miscellaneous objects that fell from a moving vehicle.

In terms of injury outcomes, as was the case in "failure to stop", sudden braking initiates accidents with small amount of fatalities and serious injuries. The biggest part of road users remains uninjured or leave the crash scene with minor injuries. However this does not include any long-term effects of the accident occurrence. Most road users were car occupants as previously, however there is a greater proportion of LGV, HGV, and bus occupants as well as motorcyclists and cyclists. Among those most are male (71.7\%), 18.4\% are female and the rest remained unspecified in the file.

The primary contributory factors that nested the accidents according to Contributory Factors (STATS19) 2005 form are presented in table 4. Sudden brake application of another vehicle is the most common contributory factor leading to the sudden brake application of the vehicle that leads to the immediate collision, suggesting a transition effect of the phenomenon that 
leads to the accident. Too close car-following behaviour is associated too and is the second most common contributory factor, followed by failures to judge others path and inadequate or masked signs. Other factors including overspeeding and distractions are common too as in the "failure to stop" cases, while a case-by-case examination of each case file, revealed an element of loss of control in some cases. That is the tendency of sudden braking to be followed by loss of vehicle control and most of those cases were fatal.

In parallel, further examination of the cases by OTS investigators reveals increased contribution of emotional (table 5) and cognitive factors (table 6), while contribution of car following and speed behaviour (table 7) is about the same level as in the National Causation data. Carelessness/recklessness/thoughtlessness was found contributing between $15.8 \%$ $32.2 \%$ of interactions, panic behaviour between $7.2 \%$ and $23.6 \%$, aggressive driving between $13.2 \%$ - $15.8 \%$, while nervousness/uncertainty contributed from $2 \%$ to $11.9 \%$. Inattention was a major factor not immediately identified in the Contributory Factors (STATS19) 2005 form. Its contribution was found between 9.2\% - 42\%. Failure to judge other road users' path or speed had a contribution between $15.1 \%$ and $29.6 \%$, higher than the STATS19 form suggests, while lack of judgement for own path ranged between 2.6 and 11.2 percent, and "look but did not see" failures had a $0-8.5 \%$ contribution. The important contribution of too close car-following found previously (table 4) was confirmed (16.4\%$34.8 \%)$ as well as the contribution of speeding (5.9\%-14.4\%).

\section{Road user reaction}

Taking into account how critical the human input is in the driver-vehicle-road environment system, road user reaction is a necessary bit of information, very hard to extract accurately though. In "failure to stop" cases, almost half the road users (48\%) have no significant 
reaction as the accident phase commences (table 8). When a reaction does take place, brake application is the most common reaction. On its own, or sometimes supplemented by steering inputs, it consists $43 \%$ of all possible reactions. Accelerating or steering without braking on the other hand is comparatively rare.

In "sudden braking" cases the proportion of road users that applied brakes is much greater (60+\% of all possible reactions) than in the previous cases. In $24.7 \%$ of cases there was no significant reaction at all. Combined steering and braking inputs consist an additional $15 \%$ of reactions while steering-only reactions are minimal (table 9). In total, significant braking, coupled with steering inputs or not, make up for three quarters of driver reaction in this type of accidents.

Both datasets suffer from missing data in about $2 \%$ of their contents.

\section{DISCUSSION OF RESULTS}

Starting from the very first table of the results, one thing is transparent: road accidents are not transparent events in their causation. There are so many different variables affecting each one of those events, changing from place to place, time to time, culture to culture, vehicle to vehicle, person to person.

\section{“Failure to stop"}

Close car-following behaviour, non-adherence to traffic rules and speeding contribute to about $50 \%$ of "failures to stop" and is logical to focus on; however there is another $50 \%$ 
which does not include the above factors. Cognitive failures and errors of road user judgement have also been identified to play a significant part. This comes in accordance with ethological studies suggesting compromised decision-making ability particularly common in intersection crashes (Preusser, Williams, Ferguson, Ulmer, \& Weinstein, 1998).

Inattention is identified as a very important factor in failures to stop the vehicle in time (table 3). As this is not the first study to identify such phenomenon (Knipling et al., 1993), the introduction of more and more in-vehicle devices ranging from simple music players to internet and e-mail facilities can easily be approached with scepticism. It is hard not to acknowledge that the additional workload imposed by a vehicle interior full of "bleeps" and "buzzes" magnifies the risk for such accidents. There is a great deal of work necessary to incorporate all those components in the vehicle environment without side-effects.

In terms of road user involvement in those cases, it is clear that there is more than just car drivers to be considered for a safe road environment. Although the respected proportions of non-car drivers in the cases examined are lower than European averages of road user casualties (European Commission), still there is about 20\% of non-car occupants and vehicles to be considered. Similar proportions apply in the case of "sudden braking” with an extra involvement of LGVs.

\section{Sudden braking}

In "sudden braking” cases although a reasonable amount of contribution is identified in too close car-following behaviour (table 4), speeding related factors have very low numbers compared to the previous tables about cases of "failure to stop". The cognitive factors are at stake here in significant numbers as well, as the contribution percentages of road user failures 
to judge other's path, sudden braking as contributory factor itself and factors related to visual perception suggest. The multiple numbers of road users per case combined with the great proportion of contribution of sudden braking to others' sudden braking suggests a strong systematic domino effect in those cases. The reaction of one driver comes in accordance with the reaction of another.

This systematic phenomenon is supported by the distribution of driver reactions in respective cases. In the case of "sudden braking" accidents, braking is the most common reaction of road users. Only a quarter of the drivers have no significant reaction in the accident sequence. In the case of "failure to stop" initiated accidents, almost half the road users did not even apply brakes (at least not significantly). When some reaction took place, it was only brake application most of the time. This result comes somewhat in contrast with a field study that suggests brake application in tandem with steering wheel inputs as a common evasive action of drivers (Muttart, 2005), although in that case the methodology was constrained in the monitoring of an urban junction only. Overall, the high proportion of non-evasive reactions raises considerations about the value of investments in systems based on driver braking (such as EBA).

\section{CONCLUSIONS: WHAT ACTIVE SAFETY SYSTEMS DO WE NEED?}

Facing the variety of factors and the complexity of the interactions that contribute to an accident it is hard to avoid scepticism about the degree in which the current automotive systems address accident causation. Although most of them are based on basic notions about 
the main factors that trigger an accident, in each of the tables presented in the results section an array of factors which are not addressed or are addressed insufficiently can be found. While it could be supported that factors like failures to stop should be ameliorated by EBA, car following distances/times could be controlled by ACC and Intelligent Speed Adaptation could minimise speeding, similar development cannot be observed to address "failures to look”, failures of judgement, driver motivation and emotional conditions, inappropriate reactions (sudden braking) or driver distraction and inattention. Specifically for the last two problems there should be two things accounted: first, the need to specify systems that improvise the deceleration-properties of the single vehicle but at the same time are harmonised with driver intentions and allow some slack for the communication of vehicle imminent status to other road users. Second, as the in-vehicle environment becomes more and more demanding visually, manually, acoustically, cognitively and/or tacitly, there is a need to integrate those elements in future systems specification. This is a major problem in modern vehicle systems design, as distraction affects lateral controllability as well (Gkikas \& Richardson, 2007), which is associated with the most deadly type of accident - loss of control/road departure (Lee, 2006). Safety systems integration with HMI controllers of invehicle devices looks promising in this area (Amditis, Kussmann, Polychronopoulos, Engstrom, \& Andreone, 2006), however such systems are still in conceptual stages/early development. The further development of driver cognitive support systems and the introduction of emotional control measures have the potential to address a significant part of accident causation at its heart.

It would be unfair not to acknowledge that conceptually ACC and EBA seem ideal against longitudinal control failures. The problem is that they currently only touch on the surface of the problem (longitudinal control failure) and fail to address the core factors behind it. Failing 
to go below the surface (precipitating factors) only makes the problem appear in a slightly different form (Hollnagel, 2004; Wagenaar \& Reason, 1990). Unfortunately, experience in high-hazard industries has widely indicated this through horrific disasters accompanying safety design that follows this approach (Hollnagel, 2004; Whittingham, 2004). A concurrent work in Chalmers University in Sweden adopts this approach in accident investigation with the aim at active safety systems specifically (Ljung, Fagerlind, Lövsund, \& Sandin, 2007). Hopefully, this system will fill in the gaps of traditional accident investigation - such as the one this study is based on.

Overall, there is a need for more interdisciplinary work in order to constantly harmonise the three elements of road transport: human, vehicle and road environment. Furthermore, there is a need to lean towards the first element, the driver and design for them, according to them. This is a generally accepted principle. However this is rarely sufficiently applied, as "averages” are far from accommodating most drivers and customisation in active safety is in a primitive phase. It comes naturally to wonder how an $\mathrm{x}$ specification (stability, cruise control, brakes assist etc.) system can accommodate for the capabilities and limitations of the real driving population, with variety in skills and limitations similar to the general population.

\section{ACKNOWLEDGEMENT}

The OTS project is funded by the UK Department for Transport and the Highways Agency. The project would not be possible without help and ongoing support from many individuals, especially including the Chief Constables of Nottinghamshire and Thames Valley Police Forces and their officers. In addition the authors of this paper would like to thank the staff at 
Loughborough University and TRL Ltd who have helped to establish and carry out this project. The views expressed in this paper belong to the authors and are not necessarily those of the Department for Transport, Highways Agency, Nottinghamshire Police or Thames Valley Police.

\section{REFERENCES}

Amditis, A., Kussmann, H., Polychronopoulos, A., Engstrom, J., \& Andreone, L. (2006). System architecture for integrated adaptive HMI solutions. 2006 IEEE Intelligent Vehicles Symposium, Meguro-ku, Japan. 13-18.

Barnes, J. (2006). An exploratory study of road crash survivors; injury outcomes and quality of life. Unpublished PhD Thesis, Loughborough University.

Barnes, J., \& Thomas, P. (2006). Quality of life outcomes in a hospitalized sample of road users involved in crashes. 253-268.

Blincoe, L. J., Seay, A., Zaloshnja, E., Miller, T., Romano, E., \& Luchter, S. (2002). The economic impact of motor vehicle crashes, 2000 No. DOTHS 809446). National Highway Traffic Safety Administration.

BOSCH. (2000). In Bauer H. (Ed.), BOSCH automotive handbook. Stuttgart: Robert Bosch $\mathrm{GmbH}$.

Breakwell, G. M., Hammond, S., \& Fife-Schaw, C. (2000). Research methods in psychology (2nd ed.). London ; Thousand Oaks, Calif.: Sage Publications.

Breuer, J. J., Faulhaber, A., Frank, P., \& Gleissner, S. (2007). Real world benefits of brake assistance systems. Proceedings of the 20th Enhanced Safety of Vehicles Conference, Lyon. (Paper Number 07-0103) 
Broughton, J. (1997). A new system for recording contributory factors in road accidents. , 9A(Part 5) 53-70.

Carsten, O. M. J., Tight, M. R., Southwell, M. T., \& Plows, B. (1989). Urban accidents: Why do they happen. Basingstoke, Hants: AA Foundation for Road Safety Research.

Delphi active safety products for automotive manufacturers. Retrieved 12/06/2007, 2007, from http://delphi.com/manufacturers/auto/safety/active/

European Commission. CARE-road accident database. Retrieved March 14th, 2007, from http://ec.europa.eu/transport/roadsafety/road_safety_observatory/care_en.htm

Evans, L. (2004). Traffic safety. Bloomfield Hills, Michigan: Science Serving Society.

Fatality analysis reporting system (FARS) web-based encyclopedia. data files and procedures to analyse them. (2005). Retrieved 30/11/2006, 2006, from http:wwwfars.nhtsa.dot.gov/

Fuller, R. (1984). A conceptualization of driving behaviour as threat avoidance. Ergonomics, 27(11), 1139.

Gibson, J. J., \& Crooks, L. E. (1938). A theoretical field-analysis of automobile-driving. American Journal of Psychology, 51, 453-471.

Girard, Y. (1993). In-depth investigations of accidents: The experience of INRETS at salonde provence. Safety Evaluation of Traffic Systems, Traffic Conflicts and Other Measures; Proceedings of the International Workshop on Theories and Concepts on Traffic Safety (ICTCT), Salzburg.

Gkikas, N., Hill, J., \& Richardson, J. (2008). Getting back to basics: Using road accident investigation to identify the desirable functionality of longitudinal control systems. In D. de Waard, F. O. Flemisch, B. Lorenz, H. Oberheid \& K. A. Brookhuis (Eds.), Human factors for assistance and automation. (pp. 203-216). Maastricht, the Netherlands: Shaker Publishing. 
Gkikas, N., \& Richardson, J. (2007). The impact of conversation on driver distraction. In P. D. Bust (Ed.), Contemporary ergonomics 2007 (pp. 115-120). London: Taylor \& Francis.

Godthelp, H., Milgram, P., \& Blaauw, G. J. (1984). The development of a time-related measure to describe driving strategy. Human Factors, 26(3), 257-268.

Hickford, A. J., \& Hall, R. D. (2004). Road safety research report no 43. review of the contributory factors system. London: Department for Transport [DfT].

Hill, J. R., Thomas, P. D., Smith, M., \& Byard, N. (2006). The methodology of on the spot accident investigations in the UK. Enhanced Safety in Vehicles 2001, Amsterdam.

Hillard, P. J., Logan, D., \& Fildes, B. (2005). The application of systems engineering techniques to the modelling of crash causation. In L. Dorn (Ed.), Driver behaviour and training (pp. 407-415). Aldershot: Ashgate,.

Hollnagel, E. (2004). Barriers and accident prevention. Aldershot: Ashgate.

Honda safety - active safety. Retrieved 12/06/2007, 2007, from http://corporate.honda.com/safety/details.aspx?id=active_safety

Kirwan, B. (1994). A guide to practical human reliability assessment. London: Taylor \& Francis.

Knipling, R. R., Mironer, M., Hendricks, D. L., Tijerina, L., Everson, J., Allen, J. C., et al. (1993). Assessment of IVHS countermeasures for collision avoidance: Rear-end crashes No. DOT HS 807 995). Washington, DC: National Highway Traffic Safety Administration.

Lee, J. D. (2006). Driving safety. In R. S. Nickerson (Ed.), Reviews of human factors and ergonomics (pp. 173-218). Santa Monica, USA: Human Factors and Ergonomics Society. 
Lie, A., Tingvall, C., Krafft, M., \& Kullgren, A. (2006). The effectiveness of electronic stability control (ESC) in reducing real life crashes and injuries. Traffic Injury Prevention, 7(1), 38-43.

Ljung, M., Fagerlind, H., Lövsund, P., \& Sandin, J. (2007). Accident investigations for active safety at Chalmers - new demands require new methodologies. Vehicle System Dynamics, 45(10), 881.

Maycock, G. (1995). Contributory factors in accidents; police databases (Project Report No. PR/SE/083/95). Crowthorne: Transport Research Laboratory.

Muttart, J. W. (2005). Factors that influence drivers' response choice decisions in video recorded crashes. Human factors in driving, telematics, and seating comfort (pp. 33-50). Warrendale, PA: SAE International.

Neilson, I., \& Condon, R. (2000). Desirable improvements in road accident and related data (Research Paper No. 1). London: Parliamentary Advisory Council for Transport Safety. Otte, D. (1999). Description of in-depth investigation team ARU/Medical University Hannover No. 1). Hannover: Medical University Hannover.

Page, Y., Foret-Bruno, J. \& Cuny, S. Are expected and observed effectiveness of emergency brake assist in preventing road injury accidents consistent? Retrieved 02/05/2007, 2007, from http://www-nrd.nhtsa.dot.gov/pdf/nrd-01/esv/esv19/05-0268-O.pdf

Preusser, D. F., Williams, A. F., Ferguson, S. A., Ulmer, R. G., \& Weinstein, H. B. (1998). Fatal crash risk for older drivers at intersections. Accident; Analysis and Prevention, 30(2), 151-159.

Reason, J. (1990). Human error. New York: Cambridge University Press.

Senders, J. W., Kristofferson, A. B., Levison, W. H., Dietrich, C. W., \& Ward, J. L. (1967). The attentional demand of automobile driving. Highway Research Record, 195, 15-33. 
Society for Automotive Engineers. (1999). ESP electronic stability programme. Driving safety systems (pp. 206-242). Germany: Robert Bosch GmbH.

Thomas, P. (2006). Crash involvement risks of cars with electronic stability control systems in Great Britain. International Journal of Vehicle Safety, 1(4), 267-281.

United States. Columbia Accident Investigation Board. (2003). In Godwin R. (Ed.), Columbia accident investigation board : Report. Burlington, Ont.: Apogee Books.

van Winsum, W., Brookhuis, K. A., \& de Waard, D. (2000). A comparison of different ways to approximate time-to-line crossing (TLC) during car driving. Accident Analysis \& Prevention, 32(1), 47-56.

van Winsum, W., \& Brouwer, W. (1997). Time headway in car following and operational performance during unexpected braking. Perceptual and Motor Skills, 84(3 PART II), 1247-1257.

van Winsum, W., \& Godthelp, H. (1996). Speed choice and steering behavior in curve driving. Human Factors, 38(3), 434-441.

van Winsum, W., \& Heino, A. (1996). Choice of time-headway in car-following and the role of time-to-collision information in braking. Ergonomics, 39(4), 579-592.

Wagenaar, W. A., \& Reason, J. T. (1990). Types and tokens in road accident causation. Ergonomics, 33(10-11), 1365-1375.

Weir, D. H., \& McRuer, D. T. (1970). Dynamics of driver vehicle steering control. Automatica, 6(1), 87-98.

Weir, D. H., \& Mcruer, D. T. (1973). Measurement and interpretation of driver-vehicle system dynamic-response. Human factors, 15(4), 367-378.

Whittingham, R. B. (2004). The blame machine : Why human error causes accidents. Oxford: Elsevier Butterworth-Heinemann. 
Wilding, P. (2002). The 2002 quality review of road accident injury statistics interim report: Extension of timetable. London: Department for Transport. 


\section{LIST OF TABLES}

Table 1. The predominant contributory factors in accidents of "failure to stop" (adapted from Gkikas et al., 2008)

\begin{tabular}{lrc}
\hline Factor & Percent & Cumulative percent \\
\hline Following too close & 26.5 & 26.5 \\
Disobeyed traffic signal & 15 & 41.5 \\
Travelling too fast & 12.8 & 54.3 \\
Careless, reckless or in a hurry & 11.3 & 65.6 \\
Failed to look & 8.2 & 73.8 \\
Exceed speed limit & 5 & 78.8 \\
Failed to judge other person's path & 3.9 & 82.7 \\
Sudden braking & 2.1 & 84.8 \\
Slippery road & 2 & 86.8 \\
Stolen vehicle & 1.6 & 88.4 \\
Aggressive driving & 1.5 & 89.9 \\
Learner driver & 1 & 90.9 \\
\hline Total & & \\
\hline
\end{tabular}

\footnotetext{
${ }^{4}$ The rest $9.1 \%$ consists of factors with contribution below $1 \%$.
} 
Table 2. Contribution of cognitive failures in "failure to stop" accidents

\begin{tabular}{r|rrrr}
\hline & $\begin{array}{r}\text { \% Definitely } \\
\text { causative }\end{array}$ & $\begin{array}{r}\text { \% Probably } \\
\text { causative }\end{array}$ & $\begin{array}{c}\text { \% Possibly } \\
\text { causative }\end{array}$ & Total \\
\hline Inattention & 19.5 & 30.6 & 23.2 & 73.3 \\
Failure to judge other person's & 15.8 & 8.8 & 7 & 31.6 \\
path or speed & & & & \\
Failure to look & 5.6 & 8.7 & 14.4 & 28.7 \\
Lack of judgement of own path & 7.8 & 7.4 & 11.5 & 26.7 \\
Look but did not see & 2.2 & 7.4 & 14.5 & 24.1 \\
\hline
\end{tabular}

Table 3. Contribution of emotional factors in "failure to stop" accidents

\begin{tabular}{r|rrrrr}
\hline & $\begin{array}{r}\text { \% Definitely } \\
\text { causative }\end{array}$ & $\begin{array}{r}\text { \% Probably } \\
\text { causative }\end{array}$ & $\begin{array}{r}\text { \% Possibly } \\
\text { causative }\end{array}$ & Total \\
\hline Aggressive driving & 0.6 & 3.6 & 4.2 & 8.4 \\
In a hurry & 1.7 & 8.8 & 8.8 & 19.3 \\
Carelessness, reckless or & 18.6 & 17.7 & 14.1 & 50.4 \\
thoughtless & & & & & \\
\hline
\end{tabular}


Table 4. The main contributory factors in "sudden braking" accidents (adapted from Gkikas

et al., 2008)

\begin{tabular}{l|rr}
\hline Factor & Percent & Cumulative Percent \\
\hline sudden braking & 35.5 & 35.5 \\
following too close & 24.3 & 59.8 \\
failed to judge other person's path or speed & 7.9 & 67.7 \\
inadequate or masked signs or road markings & 4.6 & 72.3 \\
careless, reckless or in a hurry & 4.6 & 76.9 \\
exceeded speed limit & 3.3 & 80.2 \\
distraction outside vehicle & 2.6 & 82.8 \\
aggressive driving & 2.6 & 85.4 \\
road layout (e.g. bend, hill, narrow carriageway) & 2.6 & 88.0 \\
travelling too fast for conditions & 2.6 & 90.6 \\
Animal or object in carriageway & 2.0 & 92.6 \\
slippery road (due to weather) & 2.0 & 94.6 \\
Vision affected by road layout (e.g. bend, winding road, hill crest) & 2.0 & 96.6 \\
junction overshoot & 2.0 & 98.6 \\
Cyclist entering road from footway & .7 & 99.3 \\
failed to look properly & .7 & 100 \\
\hline Total & & \\
\hline & & \\
\hline
\end{tabular}

Table 5: Contribution of emotional factors in "sudden braking" accidents

\begin{tabular}{r|rrrr}
\hline & $\begin{array}{r}\text { \%definitely } \\
\text { causative }\end{array}$ & $\begin{array}{c}\text { \%probably } \\
\text { causative }\end{array}$ & $\begin{array}{c}\text { \%possibly } \\
\text { causative }\end{array}$ & total \\
& 15.8 & 3.3 & 13.2 & 32.3 \\
Panic behaviour & 7.2 & 7.2 & 9.2 & 23.6 \\
aggressive driving & 13.2 & 0 & 2.6 & 15.8 \\
nervous or uncertain & 2 & 5.3 & 4.6 & 11.9 \\
\hline
\end{tabular}


Table 6: Contribution of cognitive failures in "sudden braking" accidents

\begin{tabular}{r|rrrr}
\hline & $\begin{array}{r}\text { \%definitely } \\
\text { causative }\end{array}$ & $\begin{array}{r}\text { \%probably } \\
\text { causative }\end{array}$ & $\begin{array}{c}\text { \%possibly } \\
\text { causative }\end{array}$ & total \\
\hline inattention & 9.2 & 16.4 & 16.4 & 42 \\
failure to judge others path or & 15.1 & 7.9 & 6.6 & 29.6 \\
lack of judgement of own path & 2.6 & 0 & 8.6 & 11.2 \\
look, but did not see & 0 & 2.6 & 5.9 & 8.5 \\
\hline
\end{tabular}

Table 7: Contribution of tactical/strategic-level behaviour in "sudden braking” accidents

\begin{tabular}{r|rrrr}
\hline & $\begin{array}{r}\text { \%definitely } \\
\text { causative }\end{array}$ & $\begin{array}{c}\text { \%probably } \\
\text { causative }\end{array}$ & causative & \\
& 16.4 & 12.5 & 5.9 & 34.8 \\
close & & & & \\
excessive & 5.9 & 4.6 & 3.9 & 14.4 \\
speed & & & & \\
\hline
\end{tabular}


Table 8. Percentage distribution of road users' reaction in "failure to stop" cases

Frequency Percent Valid Percent

\begin{tabular}{lrrr}
\hline No sig brkng, strng or acc & 518 & 47.1 & 48.2 \\
Accelerated (also steering somewhat to the Right) & \multicolumn{1}{c}{. } & .8 & .8 \\
Steered Right (also Accelerating somewhat) & 3 & .3 & .3 \\
Steered Right without significant braking or acceleration & 10 & .9 & .9 \\
Steered Right (also Braking somewhat) & 13 & 1.2 & 1.2 \\
Braked (also steering somewhat to the Right) & 29 & 2.6 & 2.7 \\
Braked without significant change in steering & 399 & 36.3 & 37.1 \\
Braked (also steering somewhat to the Left) & 34 & 3.1 & 3.2 \\
Steered Left (also Braking somewhat) & 13 & 1.2 & 1.2 \\
Steered Left without significant braking or acceleration & 2 & .2 & .2 \\
Steered Left (also Accelerating somewhat) & 3 & .3 & .3 \\
Accelerated (also steering somewhat to the Left) & 12 & 1.1 & 1.1 \\
Accelerated without significant change in steering & 5 & .5 & .5 \\
Unknown & 25 & 2.3 & 2.3 \\
Total & 1075 & 97.8 & 100.0 \\
Missing System & 24 & 2.2 & \\
\hline Total & 1099 & 100.0 & \\
\hline
\end{tabular}


Table 9. Percentage distribution of road users' reaction in “sudden braking” cases

\begin{tabular}{|c|c|c|c|}
\hline & Frequency & Percent & Valid Percent \\
\hline $\begin{array}{l}\text { No sig brkng, strng or acc: stayd clse } \\
\text { to orig line or curve }\end{array}$ & 37 & 24.3 & 24.7 \\
\hline $\begin{array}{l}\text { Steered Right (also Braking } \\
\text { somewhat) }\end{array}$ & 2 & 1.3 & 1.3 \\
\hline $\begin{array}{l}\text { Braked (also steering somewhat to the } \\
\text { Right) }\end{array}$ & 11 & 7.2 & 7.3 \\
\hline $\begin{array}{l}\text { Braked without significant change in } \\
\text { steering }\end{array}$ & 92 & 60.5 & 61.3 \\
\hline $\begin{array}{l}\text { Braked (also steering somewhat to the } \\
\text { Left) }\end{array}$ & 3 & 2.0 & 2.0 \\
\hline Steered Left (also Braking somewhat) & 1 & .7 & .7 \\
\hline $\begin{array}{l}\text { Steered Left without significant braking } \\
\text { or acceleration }\end{array}$ & 2 & 1.3 & 1.3 \\
\hline Unknown/missing data & 4 & 2.6 & 2.6 \\
\hline Total & 152 & 100.0 & 100.0 \\
\hline
\end{tabular}

